\title{
Model, Instruments, and Unity Index and Their Impact on the Unity Policy
}

\author{
Habibah Abdul Rahim¹, Bity Salwana Alias², Mohd Radzi Ishak², Zaida Nor Zainudin ${ }^{3}$ \\ ${ }^{1}$ Ministry of Education, Putrajaya, Malaysia \\ ${ }^{2}$ Faculty of Education, Universiti Kebangsaan Malaysia, Selangor, Malaysia \\ ${ }^{3}$ Faculty of Educational Studies, Universiti Putra Malaysia, Selangor, Malaysia \\ Email: bity@ukm.edu.my
}

How to cite this paper: Rahim, H. A., Alias, B. S., Ishak, M. R., \& Zainudin, Z. N. (2019). Model, Instruments, and Unity Index and Their Impact on the Unity Policy. Creative Education, 10, 2750-2759. https://doi.org/10.4236/ce.2019.1012201

Received: October 18, 2019

Accepted: November 25, 2019

Published: November 28, 2019

Copyright (c) 2019 by author(s) and Scientific Research Publishing Inc. This work is licensed under the Creative Commons Attribution International License (CC BY 4.0).

http://creativecommons.org/licenses/by/4.0/

\section{Open Access}

\begin{abstract}
The discussion on unity has never come to an end. To date, various actions have been taken to strengthen unity. Yet the direction of strengthening unity is still blurry whereas the measurement of unity in Malaysia remains a challenge. In 2014, the Education Planning and Research Division (EPRD), Ministry of Education Malaysia (MOE) through Unity Level Measurement Survey led to the success of developing instruments to produce an index as well as in developing a Unity Model of Teachers and Student. The index can be interpreted to determine unity level of students and teachers. To date, KPM has succeeded in producing the unity index for 2014, 2016, and 2018. Besides sharing KPM's achievements, this paper discussed on student unity index for 2014, 2016, and 2018 as well as the impact of the index on the unity initiative under the Malaysia Education Blueprint (PPPM) 2013-2025. The unity index and model are also referred by the other Divisions at MOE to streamline the Student Integration Plan for Unity, developing Guideline Book to Strengthen Unity through Islamic Education Subjects and Moral Education, developing Guidelines for Unity Practices in Schools, Conducting Yearly Unity Practice Inspections at Schools, and developing Unity Roadmap in Education. Various parties also refer to these models and instruments in conducting their studies on unity.
\end{abstract}

\section{Keywords}

Education, Education Unity Model, Instrument to Measure Unity, Index, Input to Strengthen Program

\section{Introduction}

To cope with the multiracial nation, various efforts have been taken to foster unity. The effort is not only focusing on the language used, but also on promoting 
compromise between different races (Education Policy Planning and Research Division, 2006). This is because unity is very important in establishing peace and harmony in a country (Shah \& Maimun, 2016). Unity should start at school. However, the study showed that co-operation and tolerance among school community are still weak, especially in the areas of administrative and infrastructure management that create a hostile environment which affects student learning and academic achievement (Marlina \& Norasmah, 2018). Therefore, education system that focuses on reducing racial difference plays an important role in strengthening unity (Educational Policy Planning and Research Division, 2012). The education program must always be on the basis of promoting unity, tolerance, care, positivity, patriotism, and pride in students towards the nation. According to Malaysia Ministry of Education Policy (2017), among the strategies to strengthen unity through education are making it compulsory to use one similar language to communicate; requiring all schools to use national curriculum; requiring all schools to perform the same examination; requiring the usage of national language in educational institutions including in vernacular school; requiring all students to pass nation language subjects in public examinations; prioritizing national school as a choice for primary school; understanding the diversity of nations and national history through history subject; applying unity elements in learning; improving the learning of national language; learning ethnic language upon request of at least 15 parents; making school as a community institution to carry out a variety of healthy social activities; extending, strengthening and expanding co-curricular activities to foster unity; applying elements of patriotism through various educational programs; and integrating co-curricular programs between schools.

The strategy is further enhanced by the initiative of strengthening unity as stated in Educational Planning Development Blueprint (2013-2025). Unity program has been expanded through collaboration between Ministry of Education, State Education Department, District Education Office, and schools. In order to measure the effectiveness of the programs implemented, the Education Policy Planning and Research Division (EPRD), Ministry of Education (MOE) is given the responsibility to measure the level of unity among teachers and school children (Ministry of Education Malaysia, 2012).

Figure 1 shows Unity Model for School Teachers and Students (EPRD, MOE 2014). This model was adopted during the development of instruments to measure unity among teachers and students. The development of instruments involved several discussions between EPRD, MOE and various parties including the National Unity and Integration Department (JPNIN), Institute of Strategic and International Studies (ISIS) Malaysia, and academicians from public and private universities. In addition, based on the consent during the discussions, items, subconstructs and constructs, as illustrated in the model, are analyzed repeatedly using the Analysis Moment Structure (AMOS) software and Winsteps software to ensure high reliability and validity of the instruments.

According to the model, unity is the output when multi-racial teachers and 


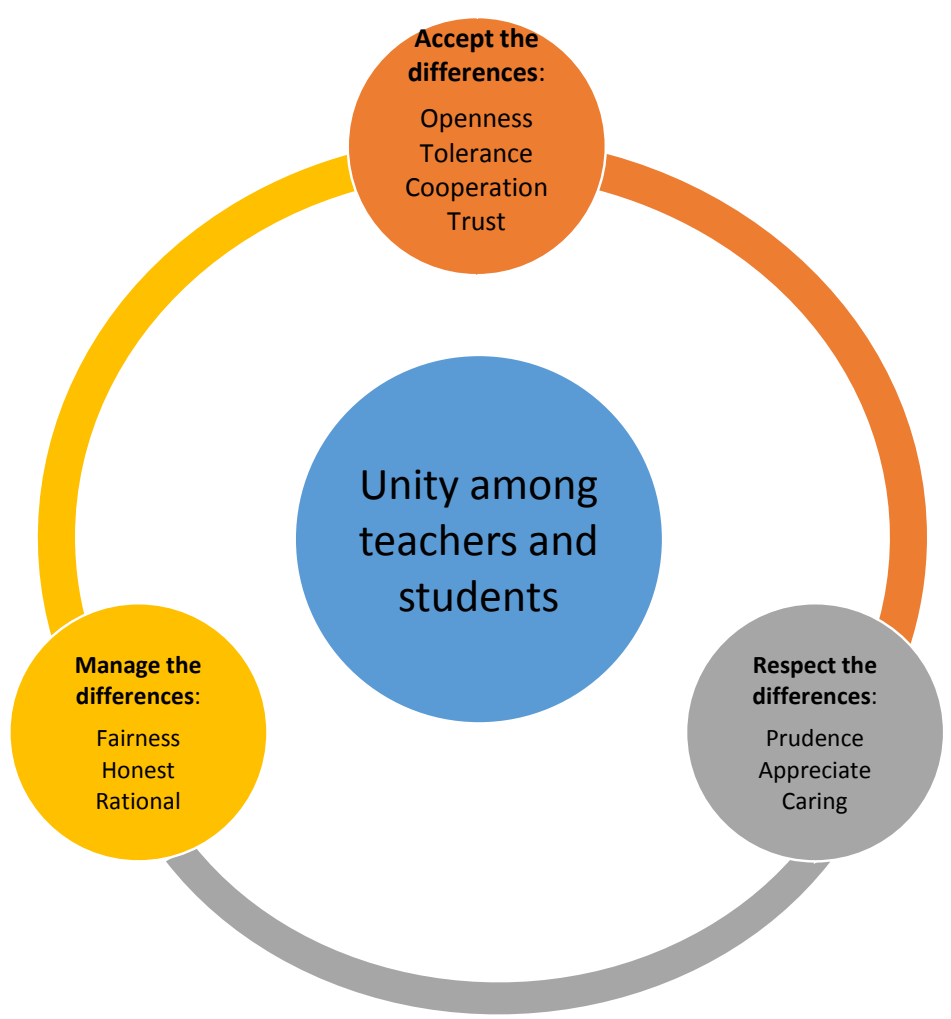

Figure 1. Unity model for school teachers and students (2014).

students are able to accept, respect, and manage cultural, religious and linguistic differences during their interaction with other races in school or out of school. The model shows that the three main constructs for unity are to accept, respect and manage differences. Each major construct has its own subconstruct (please refer to Figure 1) which is values that need to be nurtured to strengthen unity among school teachers and students.

By referring to the model, to accept differences, teachers and students must have values such as openness, tolerance, trust, and cooperation despite their racial, cultural, religious and linguistic differences.

To respect the differences, teachers and students of different races must have values such as prudence, appreciation and care for others despite racial, cultural, religious and linguistic differences.

Finally, to manage the differences, teachers and students of different races must have values such as fairness, honesty, and rationality despite racial, cultural, religious and linguistic differences.

Instruments (Questionnaire for Primary School Student and Questionnaire for Secondary School Student) to measure unity have been developed since 2012. After piloting for four times, finally in 2014, the instruments have achieved high level of reliability and validity, and can be used to collect data to measure unity among teachers and students. As shown in the model, items contained in all questionnaires enable unity to be measured based on the main constructs, i.e. accepting, respecting and managing differences. The main constructs are measured by sub- 
contracts which are the values required for unity which are openness, tolerance, cooperation, trust, appreciate, caring, prudence, fairness, honest, and rational.

Model, instruments for measuring unity (2014) and unity index for 2014, 2016 and 2018 are also being referred by various parties especially those who conduct unity studies. This paper however focuses on unity among school students only.

\section{Methodology}

In 2018, as suggested by Krejcie and Morgan (1970), this survey study involved 5662 primary school students and 5525 secondary school students. The total number of respondents is 11,187. Quantitative data was collected from randomly stratified samples i.e. by state, district, location and school type. The number of school samples is determined by the school population in each state and region (Sabitha, 2005; Sekaran, 2003). In each school, the number of respondents is 12 students. Other criteria taken into account in selecting the respondents are levels of education, which means those who have almost completed their education either at the primary or secondary level were selected. In school comprising multi-racial students, once again stratified random selection was applied. The purpose is to ensure a balanced number of respondents based on races. Schools with limited diversity or consisted of one race in majority, samples of students were randomly selected.

In 2014, the study involved 2,021 primary and 2618 secondary school students, totaling to 4639 students. While in 2016, this study involved 2961 primary school students and 3584 secondary school students with a total of 6545 students.

All three studies used the same questionnaires. The instruments contain two sections, which are Part A and Part B. Part A is to get information on school and pupils backgrounds, while Part B is to collect data that can be used to determine the degree of unity Statistical Package for the Social Sciences (Pallant, 2001). SPSS version 22.0 and Winsteps version 3.80.1 were used for data analysis.

\section{Unity Index of School Teachers and Students}

Table 1 shows the index for unity, the index for accepting the differences, respecting the differences and managing the differences, and the index for the values needed to promote unity. As agreed by all experts, an index of 0.0 to 2.5 was interpreted as low, $2.6-5.0$ as moderately low, $5.1-7.5$ as moderately high, while 7.6 - 10.0 was interpreted as high.

As shown in the table, all indexes for 2018 are lower than the index for 2014 and 2016. Unity index for primary school students is 5.3 compared to 6.6 in 2014 and 6.0 in 2016. Whereas for secondary students, the index is 5.2 in 2018, 6.5 in 2014 and 6.1 in 2016 . However, according to the interpretation, all the indexes are still moderately high. The findings also showed that the index has dropped, raising some concern especially those directly responsible for strengthening unity among students. This analysis shows that in general, unity among students has not been enhanced and requires more drastic action to ensure that the index does not continue to decline from year to year. 
Table 1. Student unity index 2014, 2016, and 2018.

\begin{tabular}{|c|c|c|c|c|c|c|}
\hline \multirow{3}{*}{$\begin{array}{l}\text { Construct and } \\
\text { Subconstruct }\end{array}$} & \multicolumn{6}{|c|}{ Index } \\
\hline & \multicolumn{2}{|c|}{2014} & \multicolumn{2}{|c|}{2016} & \multicolumn{2}{|c|}{2018} \\
\hline & $\begin{array}{l}\text { Primary } \\
\text { Student }\end{array}$ & $\begin{array}{l}\text { Secondary } \\
\text { Student }\end{array}$ & $\begin{array}{l}\text { Primary } \\
\text { Student }\end{array}$ & $\begin{array}{l}\text { Secondary } \\
\text { Student }\end{array}$ & $\begin{array}{l}\text { Primary } \\
\text { Student }\end{array}$ & $\begin{array}{c}\text { Secondary } \\
\text { Student }\end{array}$ \\
\hline Openness & 5.8 & 5.8 & 5.1 & 5.3 & 4.7 & 5.1 \\
\hline Tolerance & 6.2 & 6.4 & 5.6 & 5.6 & 5.0 & 5.6 \\
\hline Cooperation & 6.6 & 6.4 & 5.6 & 5.9 & 4.8 & 5.2 \\
\hline Trust & 6.6 & 6.4 & 5.3 & 5.2 & 4.7 & 4.8 \\
\hline Acceptance & 6.3 & 6.3 & 5.4 & 5.5 & 4.8 & 5.2 \\
\hline Prudence & 7.1 & 7.2 & 6.8 & 7.4 & 5.8 & 5.5 \\
\hline Appreciate & 6.7 & 6.9 & 6.5 & 6.6 & 5.7 & 5.0 \\
\hline Caring & 6.9 & 6.9 & 6.4 & 6.3 & 5.5 & 5.0 \\
\hline Respect & 6.9 & 7.0 & 6.6 & 6.8 & 5.6 & 5.2 \\
\hline Fairness & 6.5 & 6.4 & 6.1 & 6.1 & 5.4 & 4.9 \\
\hline Honest & 6.8 & 6.3 & 6.6 & 6.4 & 5.8 & 5.5 \\
\hline Rational & 6.4 & 6.6 & 6.1 & 6.2 & 5.3 & 5.2 \\
\hline Manage & 6.6 & 6.4 & 6.3 & 6.2 & 5.5 & 5.2 \\
\hline Unity & 6.6 & 6.5 & 6.0 & 6.1 & 5.3 & 5.2 \\
\hline
\end{tabular}

From the table, it can be seen that whether for 2014, 2016, and 2018, acceptance index for primary school students and secondary school students was lower than the respecting differences index and managing differences index. Analysis on the values required for unity showed that both categories of students achieve the lowest index for openness. This finding showed that students are still in difficulties to accept differences and are still not open to cultural, religious and linguistics differences. This phenomenon is likely to be a major contributor to unity which has not yet reached a high level among primary and secondary students.

Comparisons between 2014, 2016 and 2018 showed that overall acceptance index has dropped by 0.8 from 6.3 (2014) to 5.5 (2016) and by 0.3 from 2016 to 2018 (index $=5.2$ ). This is a relatively large decline, but the index is still at moderately high level. Acceptance index for primary school students and secondary school students were the same (6.3) in 2014 but the index for primary school students was lower compared to secondary school students in 2016 and 2018. The overall index for respecting the difference also decreased year by year for both primary and secondary school students. Referring to Table 1 as well, the index for respecting the differences for primary school students dropped more than that for secondary school students, which was by 0.3 and 0.2 respectively (from 2014 to 2016), whereas from 2016 to 2018, the dropped rate was higher for secondary school students (dropped by 1.6) compared to primary 
school students (dropped by 1.0). Analys is also found that in overall, the ability to manage the differences decreased but with smaller rate than the other two constructs. The index for primary school students only decreased by 0.3 (from 2014 to 2016) and by 0.8 (from 2016 to 2018). For secondary school students, the index was decreased by 0.2 (from 2014 to 2016) and by 1.0 from 2016 to 2018 . This index illustrates that the ability to manage the differences is also at moderately high.

An analysis was also made to determine the index for the unity values. It was found that, for primary and secondary students, whether for 2014, 2016 or 2018, there is a decrease in the index for all the values except for "prudence" and "honest" which showed a slight increase for secondary school students from 7.2 to 7.4 (2014-2016) but dropped from 7.4 (2016) to 5.5 (2018). This finding shows that students, whether in primary or secondary schools, are still at moderately high levels for all the values required for unity.

\section{Recommendation}

The unity index obtained through the study in 2014, 2016 and 2018 implies that Ministry of Education, State Education Division, District Education Office and schools should review the implementation of entire unity program. The ability to accept differences among students is lower than the ability to respect and manage differences. This finding shows that all unity programs need to focus on increasing the ability to accept cultural, religious practices, and linguistics differences among multi-racial students. It must start at a lower level education, as stated by Nordin et al. (2018), unity ethos at Pre-school children's is to promote a feeling of unity and acceptance among the diverse society of Malaysia. It is the responsibility of the teacher at the Pre-school to instill knowledge that the children need to integrate and participate in a common shared national culture, values and identity of Malaysian. It also means that programs or actions that can provide opportunities for interaction between multi-racial need to be implemented more frequently. These recommendations are based on findings that students in homogeneous school (majority with one race), locations, or states with no interaction opportunities will bring to low index for acceptance differences. In particular, to strengthen unity among students, Ministry of Education, State Education Department, District Education Office and schools are advised to review the implementation of unity programs, particularly in schools, to enhance the ability to receive racial, cultural, religious, and linguistic differences among students. Existing programs such as Student Integration Plans for Unity should provide opportunities for multi-racial students to meet and understand each other. Programs should focus on efforts to increase student acceptance to racial, cultural, religious and linguistics differences. Communities around a multi-racial school can be invited to get involved in the program.

Unity programs should be implemented at a state and national level, not just at district level. This is to provide students with opportunities to mix with mul- 
ti-racial students as well as to improve their understanding on other races. Programs that can gather them together should be periodically implemented. Focus should also be given to schools located in rural areas, besides giving more opportunities to the students to involve in the activities.

Opportunities should be given to students in all kinds of schools to involve in the unity programs at all level including national or district level. Therefore they have the chances to meet and explore the uniqueness of their diversity. Frequent interactions among themselves can increase their ability to receive, respect and manage cultural, religious practices, and linguistics differences. In addition, racial integration can also be fostered through organized contests such as multi-racial cultural inventions.

Mentor-Mentee Programs that match teachers and different races students should be empowered so that the opportunities to interact and ability to accept differences can also be improved. Unity programs should also utilize Information Communication Technology (ICT) to enable multi-racial teachers and students to communicate with each other through school websites and social websites.

All schools must also enable students to enhance the use of national language. Schools that do not use national language as a medium of instruction should have a rule that encourages teachers and students to use national language in their daily conversations. This rule is to improve the fluency in speaking national language among teachers and students. This is also to ensure that all students in all kinds of schools do not face linguistic difficulties when they are at higher level of education or when they are in the job environment.

In addition to encouraging Arabic learning, opportunities are created in all SKs so students can learn multiple languages. This proposal is in line with the aspirations of pupils in the aspect of bilingual skills (PPPM, 2013-2025) that every child has at least a Malay language as a national language and a language of unity as well as English as an international language of communication. With this language proficiency level after completing schooling, pupils should be able to use Bahasa Malaysia and English in the work environment. In addition, the ministry will encourage all students to learn other languages as additional languages. This is parallel with the statement of Teo Kok Seong (2017), ethnic relations in Malaysia need to be nurtured with simplicity, acceptance and multi-ethnic solidarity. The existence of a school that aims to meet the needs of the community, whether in a district, village, housing estate and so forth indicates that schools are not in vacuum or separated from the outside world. Hence, to achieve the goal of strengthening solidarity, not only the KPM, NRD and PPD should cooperate with the school in carrying out such activities or actions, but the whole community should also play their respective roles. The actions that ministries, agencies or other parties may take are as follows:

Government should also uphold the national language as a unity language by using it in official events and in daily communication within the organization. This effort requires the commitment of all parties, especially Ministries or agen- 
cies that can promote the use of national language and create a sense of proud of using the language in the mass media.

Government should also improve programs to foster unity and integration at regional, state or national level. The program planning and implementation should focus on increasing opportunities to multi-racial community to interact. Despite the challenge to instill value of unity through face-to-face interactions with Gen $\mathrm{Z}$ who grew up in a world of technological advances, which they often connect to each without face-to-face encounters (Fariza, 2018), we can actually use multimedia to promote segments or events that can foster positive attitude toward different races.

Besides, activities at all education institutions whether public or private should also be monitored in order to avoid racism and encourage participation from all races in the activities undertaken. Rules and regulations to safeguard the welfare and needs of all races should also be enforced. Appropriate agencies under Prime Minister's Department should be created to ensure that all activities conducted within the country do not affect the sensitivities of all races. Other parties such as politicians must play their role as well by ensuring participation of all races in any entertainment events held in their respective constituencies. The wisdom of leaders bringing together people of different races, cultures, languages, religious practices, and political ideologies not only can lead to harmony among society but also indirectly increase the positive perceptions towards leaders of different races.

Parents also have their roles. They should inculcate the value of unity such as openness, tolerance, trust and cooperation to their children as stated by Mohanambal and Anuar (2017), all people must cultivate a sense of belonging, tolerance and trust in one another in the interests of national well-being beyond their own national interests. Positive feelings toward other races need to be nurtured while negative feelings towards other religions, cultures and languages should be avoided. The practice of bringing a child to a place where interaction or integration of various races takes place (such as in resorts, shopping malls, playgrounds, etc.) should be a culture among society.

\section{Conclusion}

The unity index of Malaysian school students in 2014, 2016, and 2018 showed that unity level is at a moderately high level. The ability of multi-racial students to receive cultural, religious, and linguistic differences is still relatively low compared to the ability to respect and manage these differences. Strategy must be taken to increase openness, trust, tolerance and cooperation among students. Programs that can increase students' acceptance to racial, cultural, linguistic, and religious diversity needs to be done continuously. For pupils at school level, it is the responsibility of Ministry of Education to foster unity through appropriate action without neglecting networking and collaboration with various agencies, either public or private in an effort to strengthen unity. Recognition of Ma- 
lay as a national language and unity language should not be taken lightly. Efforts must be made to enable national language to be mastered and spoken by all ethnic groups of all ages. The use of national language in official events is not only required in schools but also in all agencies, governments and private sectors. Sense of pride in national language as an official language and unity language should be cultivated at all levels of society. In the implementation of the unity program, the ability to accept the differences and the application of values of unity should always be focused. Efforts should also be made to increase the involvement of students in homogeneous schools in every unity program. Collaboration with the Ministry or other agencies needs to be strengthened so that unity programs are not only focused at school level but are extended beyond the boundaries of schools, districts, states, and even countries. In fact, every individual in a country plays a role in strengthening unity.

\section{Acknowledgements}

This research is funded by Universiti Kebangsaan Malaysia (UKM) under research scheme No. Grant PP-FPEND-2019 and Yayasan Guru Tun Hussein YGTHO/KEB/01/1-101(90).

\section{Conflicts of Interest}

The authors declare no conflicts of interest regarding the publication of this paper.

\section{References}

Education Policy Planning and Research Division (2006). Malaysian EducationalStatistics 2006. Federal Territory of Putrajaya. Ministry of Education Malaysia.

Educational Policy Planning and Research Division (2012). National Education Policy 2012. Federal Territory of Putrajaya. Ministry of Education Malaysia.

Fariza, M. S. (2018). Z Generation and Unity Issue (pp. 14-19). ICIP 2018 (International Colloquium on Integration Platform.

Krejcie, R. V., \& Morgan, D. W. (1970). Determining Sample Size for Research Activities. Educational and Psychological Measurement, 30, 607-610. https://doi.org/10.1177/001316447003000308

Marlina Binti, N. N., \& Norasmah, O. (2018). Administration and Infrastructure Facilities Management for Unity in Secondary School. Proceeding: 2nd International Conference on Education, Business, Islamic and Technology (ICEBIT 2018) Seaview Langkawi Hotel, 1-2 September 2018.

Ministry of Education Malaysia (2012). Report Malaysia Education Blueprint 2013-2025. Federal Territory of Putrajaya. Ministry of Education Malaysia.

Mohanambal, M., \& Anuar, A. (2017). 21st Century Learning History for National Unity (pp. 3067-3079). International Conference on Global Education.

Nordin, M., Abdul, R. R., Abdul, T. M. H., Abdul Razaq, A., \& Mohd, M. A. (2018). A Case Study of PERPADUAN Pre-School Settings Inculcates Multi-Ethnic Awareness among Preschoolers'. International Journal of Academic Research in Business and Social Sciences, 8, 1181-1190. https://doi.org/10.6007/IJARBSS/v8-i10/5289 
Pallant, J. (2001). A Step by Step Guide to Data Analysis Using SPSS for Windows (Version 12). Buckingham: Open University Press.

Sabitha, M. (2005). Social Science Research Methods. Petaling Jaya: Pearson Prectice Hall (Malaysia).

Sekaran, U. (2003). Research Methods for Business: A Skill-Building Approach. New York: John Wiley and Sons.

Shah, R. Z., \& Maimun, A. L. (2016). The Value of Unity in an Islamic State According to the Medina Charter Perspective (pp. 115-126). The 9th International Workshop and Conference of Asian Studies in Islamic and Arabic Education and Educational Technology (POLMED-UKM-UMSU) 2016.

Teo, K. S. (2017). Bahasa Melayu as a Tool of Unity (pp. 92-103). Prosiding: Konvensyen Memperkukuh Pasak Negara: Ke Arah Wasiat Lebih Tersurat. 